\title{
FASE-CPHG Study: identification of asthma phenotypes in the French Severe Asthma Study using cluster analysis
}

\author{
Chantal Raherison-Semjen ${ }^{1,2^{*}} \mathbb{D}$, Eric Parrat ${ }^{3}$, Cécilia Nocent-Eijnani ${ }^{4}$, Gilles Mangiapan ${ }^{5}$, Anne Prudhomme ${ }^{6}$, \\ Jean-Philippe Oster ${ }^{7}$, Corinne Aperre de Vecchi ${ }^{8}$, Cyril Maurer ${ }^{9}$, Didier Debieuvre ${ }^{10}$ and Laurent Portel ${ }^{11}$ on \\ behalf of The CPHG (College of French Non-academic Hospitals)
}

\begin{abstract}
Background: In France, data regarding epidemiology and management of severe asthma are scarce. The objective of this study was to describe asthma phenotypes using a cluster analysis in severe asthmatics recruited in a real world setting.

Methods: The study design was prospective, observational and multicentric. The patients included were adults with severe asthma (GINA 4-5) followed-up in French Non Academic Hospital between May 2016 and June 2017. One hundred and seven physicians included 1502 patients. Both sociodemographic and clinical variables were collected. Hierarchical cluster analysis was performed by the Ward method followed by k-means cluster analysis on a population of 1424 patients.

Results: Five clusters were identified: cluster $1(n=690,47 \%)$ called early onset allergic asthma (47.5\% with asthma before 12 years), cluster $2(n=153,10.5 \%)$ : obese asthma (63.5\% with BMl > $\left.30 \mathrm{~kg} / \mathrm{m}^{2}\right)$, cluster $3(n=299$, 20.4\%): lateonset asthma with severe obstructive syndrome ( $89 \%$ without atopy), cluster $4(n=143,9.8 \%)$ : eosinophilic asthma (51.7\% had more than 500 eosinophils $\left./ \mathrm{mm}^{3}\right)$, and cluster $5(n=139,9.5 \%)$ : aspirin sensitivity asthma (63\% had severe asthma attacks).
\end{abstract}

Conclusions: In our population of adults with severe asthma followed by pulmonologists, five distinct phenotypes were identified and are quite different from those mentioned in previous studies.

Keywords: Severe asthma, Phenotypes, Cluster analysis

\section{Introduction}

Asthma is a heterogeneous disease that presents with a variety of symptoms and variable response to medication.

Management of mild to moderate asthma is based on the same treatment for each patient, variable according to asthma control and exacerbations risk [1] (GINA 2018).

\footnotetext{
*Correspondence: Chantal.raherison@chu-bordeaux.fr

${ }^{1}$ Groupe Hospitalier Sud, Hôpital Haut-Lévêque CHU Bordeaux, Pessac, France
}

Full list of author information is available at the end of the article
By contrast, as patients with difficult-to-treat asthma or severe asthma had a high rate of exacerbations and poor asthma control and poor quality of life despite management, improvement in therapeutic management had leaded to better understanding in asthma phenotypes.

A decade ago, asthma phenotypes were defined by two criteria i.e. atopic status and age onset of asthma (childhood versus adulthood) (Wenzel et al.). Since then, Enfumosa Network [2] identified that patients with chronic severe asthma were more likely to be female, overweighted, less atopic and pointed out exposure to 
aspirin for some subjects. The SARP consortium in USA identified three clusters in adult patients with severe asthma [3]: early onset allergic asthma, late onset nonatopic asthma, severe asthma with fixed airflow. Then, the TENOR project found some similarities with the SARP clusters, for four of five clusters [4]. Interestingly, associations were made between asthma phenotypes and asthma-related health outcomes i.e. quality of life. In these phenotypes, atopic status but also non-white race were distinguishing variables for both children and adolescents. In Europe, some severe asthma registries have been developed in UK [5], in Belgium [6], and in Italy [7]. According to the Belgium Registry, the majority of severe asthmatics were female and atopic, revealing that description of patients depends on existence of network and inclusion of patients at baseline [6]. The same snapshot was described in the Italian Registry [7]. By contrast, in the UK registry [5], five clusters were described: atopic early onset asthma, obese with late onset asthma, least severe asthma, eosinophilic late onset-asthma and fixed airflow obstruction. They also find a poor stability in this longitudinal analysis.

In France, data regarding severe asthma management are scarce, a recent study estimated that prevalence of severe asthma was about 3.8\% [8], in line in estimated prevalence of severe asthma $3.6 \%$ in previous surveys [9]. In addition, two thirds of patients with severe asthma are managed in non-specialized environment [10]. 9.8\% (range 3.5-17.5\%) of patients with severe asthma in real life was found to be eligible for enrolment in the phase III trials [11]. FASE-CPHG (France Asthme Sévère-Collège des Pneumologues des Hôpitaux Généraux) was built in 2016 as descriptive, multicentric and observational crosssectional study in patients with severe asthma conducted in general hospitals in France.

The aim of our study was to describe the clinical phenotypes of severe asthma adults, in a real-life study in France using cluster analysis.

\section{Methods}

\section{Study population}

CPHG is a collaborative group of pulmonologists working in non-academic hospitals. One hundred and ten centers accepted to participate to the study. The methodology and descriptive analysis have been published elsewhere [12].

This study was approved by the local ethics committee (Comité Consultatif sur le Traitement de l'Information en matière de Recherche dans le domaine de la Santé (CCTIRS)) and was conducted according to the French law and guidelines on epidemiological and descriptive studies.
Pulmonologists from an extensive list of practitioners were contacted to confirm their willingness to participate in the FASE-CPHG observational study. During the inclusion period, selected pulmonologists were required to recruit all patients who meet the eligibility criteria to ensure exhaustivity. Moreover, and for the same reason, patients who refused to participate in the study were logged in a non-inclusion register.

To join the study, patients must have fulfilled all of the following criteria: aged over 18 years old with a severe asthma diagnosis according to the physician and based on Global INitiative for Asthma (GINA) [1]. All subjects were informed during a regular visit by the physician before being enrolled. Patients diagnosed with solid cancer or malignant hemopathy where excluded and also those who refuse to participate in the study.

According to GINA criteria, severe asthma is defined as asthma that requires Step 4 or 5 treatment to prevent it from becoming 'uncontrolled', or asthma that remains 'uncontrolled' despite this treatment. Uncontrolled step 3 patients were also considered as severe asthmatics as the adjustment strategy in case of uncontrolled asthma per 3 months would be to step up treatment up to step 4 . After validation by the physicians, patients only treated with short acting beta agonist were excluded from analyses as it is considered as non-severe asthma according to GINA criteria.

\section{Patient data collection}

Physician completed a secure electronic Case Report Form (eCRF), during a regular visit on patient characteristics (sociodemographic data, potential asthma triggers, medical history, comorbidities, clinical parameters, spirometry, blood eosinophils) and asthma ongoing treatment for all patients seen during the study period.

In addition, patients were required to fill in auto-questionnaires comprising items on asthma control (Asthma Control Test (ACT)), anxiety and depression (Hospital Anxiety and Depression Scale (HADS)).

\section{Data management}

Data were entered into databases managed by Kappa Santé, Paris, France. Duplicates were identified with indirectly nominative data (initial, age and sex) and reviewed with participant pulmonologists. In addition of online control present on eCRF, data were reviewed before database was frozen freeze for other errors, omissions or inconsistencies by a scientific committee.

Patients enrolled by participant physician with no completed CRF were removed from the analysis. 


\section{Statistical analysis}

All statistical analyses were performed using SAS (version 9.4, SAS Institute Inc., Carey, North Carolina, USA). $P$ value $<0.05$ was regarded as statistically significant.

Qualitative variables are summarized as raw and frequencies; number of missing data is specified. Quantitative data is expressed as numbers of analyzed values, mean with standard deviation.

Asthma control was evaluated using the ACT, a 5-item questionnaire (activity limitation, shortness of breath, night symptoms, use of rescue medication and self-perception of asthma control). Each parameter was scored from 1 (poorly control) to 5 (well controlled). The HADS was used to evaluate anxiety and depression symptoms in patients. The HADS is based on 14-items and produces two scales: one for anxiety (HADS-A) and one for depression (HADS-D). A score $\geq 11$ on either scale indicate a definitive case whereas score $<7$ generally indicates an absence of the trouble.

\section{Cluster analysis}

Eighteen variables (gender, BMI, age, age of asthma onset, severe asthma attacks with ICU, FEV1, clinical atopy, exacerbations, allergenic sensitization, aspirin intolerance, nasal polyposis, chronic rhinitis, apnea syndrome, reflux, hypertension, smoking status, and eosinophils count) have been included in the analysis. Missing data were most frequent for eosinophils count, and two methods have been performed with and without imputation data.

A hierarchical bottom-up classification method using Ward's method is then carried out, using an agglomeration (ascending) approach and a ward distance (Fig. 1). With each generation of clusters, samples are merged into larger clusters to minimize the sum of intra-cluster squares, while maximizing the sum of inter-cluster squares. In order to compare the differences between the resulting clusters, ANOVA, the Kruskal-Wallis test and The Pearson Khi Two test are used respectively for continuous parametric variables, continuous non-parametric variables and categorical variables (classes). The dendrograms were produced and were examined to help to determine the number of clusters as shown on Fig. 1.

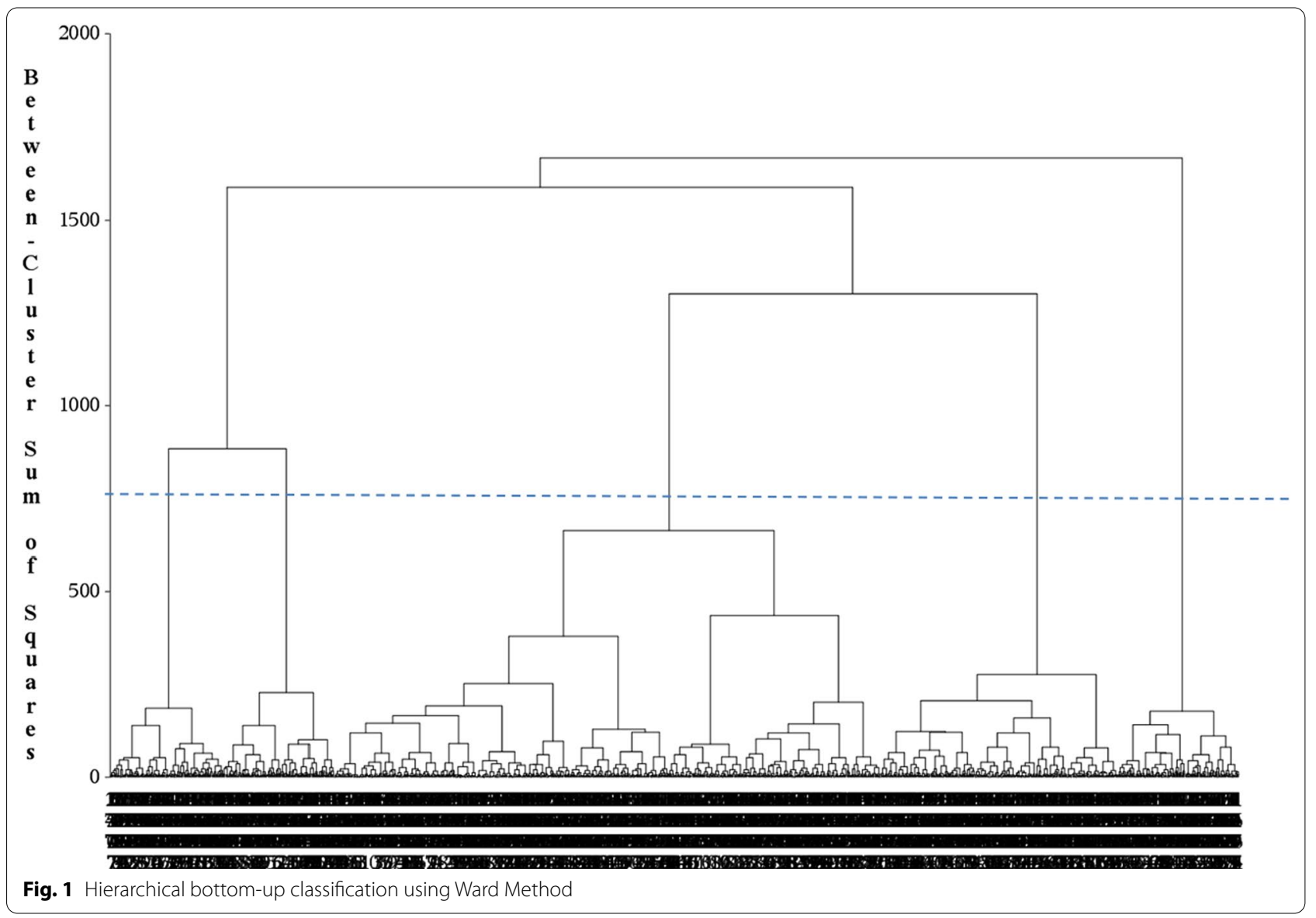


Table 1 Clinical characteristics of FASE-CPHG severe asthma clusters

\begin{tabular}{|c|c|c|c|c|c|c|c|c|}
\hline & & $\begin{array}{l}\text { Cluster } 1 \\
\text { Early onset } \\
\text { atopic } \\
(\mathrm{N}=690)\end{array}$ & $\begin{array}{l}\text { Cluster } 2 \\
\text { Obese } \\
(N=153)\end{array}$ & $\begin{array}{l}\text { Cluster } 3 \\
\text { Late-onset } \\
(\mathrm{N}=299)\end{array}$ & $\begin{array}{l}\text { Cluster } 4 \\
\text { Eosinophilic } \\
(N=143)\end{array}$ & $\begin{array}{l}\text { Cluster } 5 \\
\text { Aspirin- } \\
\text { sensitivity } \\
(\mathrm{N}=139)\end{array}$ & $\begin{array}{l}\text { Patients } \\
\mathrm{N}=1424\end{array}$ & $p$ \\
\hline \multirow[t]{2}{*}{ Gender } & Male & 229 (33.2\%) & $81(52.9 \%)$ & $112(37.5 \%)$ & 69 (48.3\%) & $40(28.8 \%)$ & $531(37.3 \%)$ & $<0.0001$ \\
\hline & Female & $461(66.8 \%)$ & $72(47.1 \%)$ & $187(62.5 \%)$ & $74(51.7 \%)$ & 99 (71.2\%) & $893(62.7 \%)$ & \\
\hline \multirow[t]{4}{*}{ BMI } & $<21 \mathrm{~kg} / \mathrm{m}^{2}$ & $23(3.3 \%)$ & $1(0.7 \%)$ & $10(3.3 \%)$ & $4(2.8 \%)$ & $6(4.3 \%)$ & $44(3.1 \%)$ & $<0.0001$ \\
\hline & $21-25 \mathrm{~kg} / \mathrm{m}^{2}$ & $278(40.3 \%)$ & $12(7.8 \%)$ & $101(33.8 \%)$ & $59(41.3 \%)$ & $44(31.7 \%)$ & 494 (34.7\%) & \\
\hline & $25-29 \mathrm{~kg} / \mathrm{m}^{2}$ & 198 (28.7\%) & $43(28.1 \%)$ & $119(39.8 \%)$ & $48(33.6 \%)$ & $57(41 \%)$ & $465(32.7 \%)$ & \\
\hline & $\begin{array}{l}\text { Obese }>30 \text { kg/m² } \\
\text { Median }\end{array}$ & $\begin{array}{l}191(27.7 \%) \\
26\end{array}$ & $\begin{array}{l}97(63.4 \%) \\
32.9\end{array}$ & $\begin{array}{l}69(23.1 \%) \\
26\end{array}$ & $\begin{array}{l}32(22.4 \%) \\
25.7\end{array}$ & $\begin{array}{l}32(23 \%) \\
26.3\end{array}$ & $\begin{array}{l}421(29.6 \%) \\
26.5\end{array}$ & \\
\hline \multirow[t]{3}{*}{ Age at baseline } & [18-40] & $216(31.3 \%)$ & $4(2.6 \%)$ & $18(6 \%)$ & $18(12.6 \%)$ & $20(14.4 \%)$ & $276(19.4 \%)$ & $<0.0001$ \\
\hline & {$[40-60]$} & 307 (44.5\%) & $62(40.5 \%)$ & 87 (29.1\%) & $59(41.3 \%)$ & $56(40.3 \%)$ & $571(40.1 \%)$ & \\
\hline & $\begin{array}{l}60 \text { years and more } \\
\text { Median }\end{array}$ & $\begin{array}{l}167(24.2 \%) \\
50\end{array}$ & $\begin{array}{l}87(56.9 \%) \\
61\end{array}$ & $\begin{array}{l}194(64.9 \%) \\
65\end{array}$ & $\begin{array}{l}66(46.2 \%) \\
59\end{array}$ & $\begin{array}{l}63(45.3 \%) \\
57.5\end{array}$ & $\begin{array}{l}577(40.5 \%) \\
56\end{array}$ & \\
\hline \multirow{3}{*}{$\begin{array}{l}\text { Age at onset of } \\
\text { asthma }\end{array}$} & $<12$ years & $359(52 \%)$ & $33(21.6 \%)$ & $28(9.4 \%)$ & $32(22.4 \%)$ & 35 (25.2\%) & 487 (34.2\%) & $<0.0001$ \\
\hline & [12-40] & $256(37.1 \%)$ & $52(34 \%)$ & 91 (30.4\%) & $67(46.9 \%)$ & $67(48.2 \%)$ & $533(37.4 \%)$ & \\
\hline & $\begin{array}{l}40 \text { years and more } \\
\text { Median }\end{array}$ & $\begin{array}{l}75(10.9 \%) \\
12\end{array}$ & $\begin{array}{l}68(44.4 \%) \\
36\end{array}$ & $\begin{array}{l}180(60.2 \%) \\
44\end{array}$ & $\begin{array}{l}44(30.8 \%) \\
30\end{array}$ & $\begin{array}{l}37(26.6 \%) \\
30\end{array}$ & $\begin{array}{l}404(28.4 \%) \\
24\end{array}$ & \\
\hline Severe asthma attacks & Ever & $362(52.5 \%)$ & $93(60.8 \%)$ & $135(45.2 \%)$ & $60(42 \%)$ & $88(63.3 \%)$ & $738(51.8 \%)$ & $<0.001$ \\
\hline FEV1, \% pred & Means ( $\pm s d)$ & $73.2( \pm 19.3)$ & $68( \pm 21)$ & $\begin{array}{l}68.2 \\
\quad( \pm 22.2)\end{array}$ & $76.7( \pm 20.2)$ & $75.7( \pm 22)$ & $<0.0001$ & \\
\hline
\end{tabular}

\section{Results}

One thousand and four hundred twenty four patients from 107 centers were included in this analysis. A five cluster model best described the dataset. Their characteristics are as shown in Table 1.

Cluster 1 comprised $47 \%$ of the cohort, had early onset allergic asthma (52\% with asthma before 12 years), cluster $2(\mathrm{n}=153,10.5 \%)$ comprised obese asthma $(63.4 \%$ with BMI $\left.>30 \mathrm{~kg} / \mathrm{m}^{2}\right)$, more often men, cluster $3(\mathrm{n}=299$, $20.4 \%$ ) had late-onset asthma with $60.2 \%$ having asthma after 40 years old, cluster $4(n=143,9.8 \%)$ comprised eosinophilic asthma (51.7\% had more than 500 eosinophils $\left./ \mathrm{mm}^{3}\right)$, and cluster $5(\mathrm{n}=139,9.5 \%)$ had aspirin sensitivity asthma (with $63 \%$ had severe asthma attacks).

Regarding allergenic sensitization, $79.3 \%$ of patients in cluster 1 had skin prick test positivity. Nasal polyposis was more reported in patients of cluster 4 , in patients having eosinophilic profile, and in cluster 5 in patients having also aspirin sensitivity. Chronic rhinitis and rhinosinusitis were more frequent in cluster 4 and 5 . By contrast, obstructive apnea syndrome was exclusively reported in cluster 2 , with others comorbidities as reflux, hypertension and smoking history (Table 2).

Food allergy and drug allergy was more associated in cluster 5 , most of the comorbidities were associated with cluster 2 i.e. diabetes, ischemic cardiopathy, and depression (Table 3).
Osteoporosis was not associated with specific cluster. The number of comorbidities was particularly high in cluster 2 . The frequency of frequent exacerbation profile was present in each cluster, however the number of exacerbations requiring an increase of treatment either oral corticosteroids or inhaled treatment was higher in eosinophilic cluster (named cluster 4) and aspirin sensitivity (cluster 5). Patients from cluster 2 had higher emergency visits compared to others patients. Absenteeism related to asthma was more frequent in patients from cluster 1 and cluster 5 .

House dust mite sensitization was more related in cluster 1 having early onset asthma, and was very low in late-onset asthma (cluster 3). Sensitization to molds and cockroaches were also lower in late-onset asthma cluster, non-atopic. The distribution of blood eosinophils is presented by cluster (Table 3). Despite a large proportion of patients having more than 500 eosinophil counts in cluster 4, eosinophilic distribution was heterogeneous across the different clusters. Among 1462 patients, $19 \%$ had missing data regarding blood eosinophils or IgE level, 55.6\% ( $\mathrm{n}=814)$ (Additional file 1: Table S1) had blood eosinophils count and IgE level, 19\% had blood eosinophils count but no IgE, and 6.4\% had IgE levels but no blood eosinophils count available. Finally, 12.7\% of the patients had low $\mathrm{TH} 2$ profile, 13\% eosinophilic non-allergic profile, $28.5 \%$ had allergic non-eosinophilic 
Table 2 Comorbidities of FASE-CPHG severe asthma clusters

\begin{tabular}{|c|c|c|c|c|c|c|c|c|}
\hline & & $\begin{array}{l}\text { Cluster } 1 \\
\text { Early onset } \\
\text { atopic } \\
(\mathrm{N}=690)\end{array}$ & $\begin{array}{l}\text { Cluster } 2 \\
\text { Obese } \\
(\mathrm{N}=153)\end{array}$ & $\begin{array}{l}\text { Cluster } 3 \\
\text { Late- } \\
\text { onset } \\
(\mathrm{N}=299)\end{array}$ & $\begin{array}{l}\text { Cluster } 4 \\
\text { Eosinophilic } \\
(N=143)\end{array}$ & $\begin{array}{l}\text { Cluster } 5 \\
\text { Aspirin- } \\
\text { sensitivity } \\
(\mathrm{N}=139)\end{array}$ & $\begin{array}{l}\text { Patients } \\
N=1424\end{array}$ & $p$ \\
\hline $\begin{array}{l}\text { Allergenic sensitization, } \\
n=1158\end{array}$ & SPT positivity & 547 (79.3\%) & 81 (52.9\%) & $33(11 \%)$ & 67 (46.9\%) & 83 (59.7\%) & $811(70 \%)$ & $<0.0001$ \\
\hline Aspirin sensitivity & Yes & $1(0.1 \%)$ & $12(7.8 \%)$ & $0(0 \%)$ & $1(0.7 \%)$ & 139 (100\%) & 153 (10.7\%) & $<0.0001$ \\
\hline Nasal polyposis & Yes & $12(1.7 \%)$ & 21 (13.7\%) & $5(1.7 \%)$ & $143(100 \%)$ & 77 (55.4\%) & $258(18.1 \%)$ & $<0.0001$ \\
\hline Allergic rhinitis & Yes & $323(46.8 \%)$ & 69 (45.1\%) & $96(32.1 \%)$ & 80 (55.9\%) & 74 (53.2\%) & 642 (45.21\%) & $<0.0001$ \\
\hline Rhinosinusitis & Yes & 137 (19.9\%) & $33(21.6 \%)$ & 55 (18.4\%) & $65(45.5 \%)$ & $62(44.6 \%)$ & $352(24.7 \%)$ & $<0.0001$ \\
\hline $\begin{array}{l}\text { Obstructive apnea syn- } \\
\text { drome }\end{array}$ & Yes & $0(0 \%)$ & $153(100 \%)$ & $1(0.3 \%)$ & $1(0.7 \%)$ & $1(0.7 \%)$ & $156(11 \%)$ & $<0.0001$ \\
\hline Reflux history & Yes & $231(33.5 \%)$ & 75 (49\%) & $\begin{array}{l}129 \\
(43.1 \%)\end{array}$ & $50(35 \%)$ & 70 (50.4\%) & $555(39 \%)$ & $<0.0001$ \\
\hline Hypertension & Yes & $119(17.2 \%)$ & 83 (54.2\%) & $\begin{array}{l}102 \\
(34.1 \%)\end{array}$ & $20(14 \%)$ & $37(26.6 \%)$ & $361(25.4 \%)$ & $<0.0001$ \\
\hline \multirow[t]{3}{*}{ Smoking history } & Active smoker & $108(15.7 \%)$ & $8(5.2 \%)$ & $32(10.7 \%)$ & $7(4.9 \%)$ & $11(7.9 \%)$ & $166(11.7 \%)$ & $<0.0001$ \\
\hline & Ex-smoker & $176(25.5 \%)$ & 61 (39.9\%) & $85(28.4 \%)$ & 49 (34.3\%) & $40(28.8 \%)$ & 411 (28.9\%) & \\
\hline & No-smoker & $406(58.8 \%)$ & 84 (54.9\%) & $\begin{array}{l}182 \\
(60.9 \%)\end{array}$ & 87 (60.8\%) & 88 (63.3\%) & 847 (59.5\%) & \\
\hline \multirow[t]{3}{*}{ Blood eosinophil count } & $<300$ & $331(48 \%)$ & $66(43.1 \%)$ & $\begin{array}{l}150 \\
(50.2 \%)\end{array}$ & $36(25.2 \%)$ & $63(45.3 \%)$ & $646(45.4 \%)$ & $<0.0001$ \\
\hline & {$[300-500]$} & $176(25.5 \%)$ & $46(30.1 \%)$ & $63(21.1 \%)$ & $33(23.1 \%)$ & $28(20.1 \%)$ & $346(24.3 \%)$ & \\
\hline & $\geq 500$ & $183(26.5 \%)$ & $41(26.8 \%)$ & $86(28.8 \%)$ & $74(51.7 \%)$ & $48(34.5 \%)$ & $432(30.3 \%)$ & \\
\hline
\end{tabular}

Table 3 Comorbidities of FASE-CPHG severe asthma clusters

\begin{tabular}{|c|c|c|c|c|c|c|c|c|}
\hline & & $\begin{array}{l}\text { Cluster } 1 \\
\text { Early onset } \\
\text { atopic } \\
(\mathrm{N}=690)\end{array}$ & $\begin{array}{l}\text { Cluster } 2 \\
\text { Obese } \\
(N=153)\end{array}$ & $\begin{array}{l}\text { Cluster } 3 \\
\text { Late- } \\
\text { onset } \\
(\mathrm{N}=299)\end{array}$ & $\begin{array}{l}\text { Cluster } 4 \\
\text { Eosinophilic } \\
(N=143)\end{array}$ & $\begin{array}{l}\text { Cluster } 5 \\
\text { Aspirin- } \\
\text { sensitivity } \\
(\mathrm{N}=139)\end{array}$ & $\begin{array}{l}\text { Patients } \\
\text { analysed } \\
n=1424\end{array}$ & p \\
\hline Fernand widal syndrome & Yes & $3(0.4 \%)$ & $6(3.9 \%)$ & $0(0 \%)$ & $16(11.2 \%)$ & $72(51.8 \%)$ & $97(6.8 \%)$ & $<0.0001$ \\
\hline Food allergy & Yes & $78(11.3 \%)$ & $17(11.1 \%)$ & $12(4 \%)$ & $14(9.8 \%)$ & $25(18 \%)$ & $146(10.3 \%)$ & $<0.01$ \\
\hline Drug allergy & Yes & $69(10 \%)$ & $28(18.3 \%)$ & $35(11.7 \%)$ & $15(10.5 \%)$ & $54(38.8 \%)$ & $201(14.1 \%)$ & $<0.0001$ \\
\hline Atopic dermatitis & Yes & $130(18.8 \%)$ & $18(11.8 \%)$ & $19(6.4 \%)$ & $19(13.3 \%)$ & $33(23.7 \%)$ & $219(15.4 \%)$ & $<0.0001$ \\
\hline $\begin{array}{l}\text { Allergic broncho-pulmonary } \\
\text { aspergillosis }\end{array}$ & Yes & $22(3.2 \%)$ & $2(1.3 \%)$ & $6(2 \%)$ & $1(0.7 \%)$ & $5(3.6 \%)$ & $36(2.5 \%)$ & 0.28 \\
\hline Vascularitis & Yes & $6(0.9 \%)$ & $1(0.7 \%)$ & $5(1.7 \%)$ & $3(2.1 \%)$ & $0(0 \%)$ & $15(1.1 \%)$ & 0.33 \\
\hline Diabetus & Yes & $46(6.7 \%)$ & $35(23 \%)$ & $42(14.1 \%)$ & $7(4.9 \%)$ & $11(8 \%)$ & $141(10 \%)$ & $<0.0001$ \\
\hline Ischemic cardiopathy & Yes & $22(3.2 \%)$ & $16(10.5 \%)$ & $17(5.7 \%)$ & $9(6.3 \%)$ & $6(4.3 \%)$ & $70(4.9 \%)$ & $<0.001$ \\
\hline Osteoporosis & Yes & $58(8.4 \%)$ & $17(11.1 \%)$ & $36(12.1 \%)$ & $23(16.1 \%)$ & $19(13.7 \%)$ & $153(10.8 \%)$ & 0.16 \\
\hline Anxiety (HAD-A) & Means (Sd) & $7.6( \pm 4.5)$ & $7.5( \pm 4.5)$ & $7.3( \pm 4.2)$ & $7( \pm 4.4)$ & $7.1( \pm 4.7)$ & $7.4( \pm 4.4)$ & 0.52 \\
\hline Depression (HAD-D) & Means (Sd) & $4.6( \pm 3.6)$ & $5.6( \pm 4.1)$ & $5.4( \pm 3.9)$ & $5.3( \pm 4.2)$ & $5.3( \pm 3.7)$ & $5( \pm 3.8)$ & $<0.01$ \\
\hline \multirow{4}{*}{$\begin{array}{l}\text { Number of comorbidities } \\
\text { (outside ENT) }\end{array}$} & 0 & $247(35.8 \%)$ & $0(0 \%)$ & $57(19.1 \%)$ & $47(32.9 \%)$ & $27(19.4 \%)$ & $378(26.6 \%)$ & \\
\hline & 1 & $212(30.8 \%)$ & $24(15.7 \%)$ & $92(30.9 \%)$ & $52(36.4 \%)$ & 42 (30.2\%) & $422(29.7 \%)$ & \\
\hline & 2 & $120(17.4 \%)$ & $33(21.6 \%)$ & $75(25.2 \%)$ & $23(16.1 \%)$ & 33 (23.7\%) & $284(20 \%)$ & \\
\hline & 3 or more & $110(16 \%)$ & $96(62.7 \%)$ & $74(24.8 \%)$ & $21(14.7 \%)$ & 37 (26.6\%) & $338(23.8 \%)$ & \\
\hline
\end{tabular}

profile and $26.9 \%$ had eosinophilic and allergic profile. Lung function results showed that the high proportion of patients having FEV $1<60 \%$ was in cluster 2 (obese patients with comorbidities) and in cluster 3 late-onset non-atopic asthma Additional file 1: Table S2). Obstructive syndrome with low FEV1/FVC ratio was more 
Table 4 History of exacerbations in FASE-CPHG severe asthma clusters

\begin{tabular}{|c|c|c|c|c|c|c|c|c|}
\hline & & $\begin{array}{l}\text { Cluster } 1 \\
\text { Early onset } \\
\text { atopic } \\
(\mathrm{N}=690)\end{array}$ & $\begin{array}{l}\text { Cluster } 2 \\
\text { Obese } \\
(N=153)\end{array}$ & $\begin{array}{l}\text { Cluster } 3 \\
\text { Late-onset } \\
(\mathrm{N}=299)\end{array}$ & $\begin{array}{l}\text { Cluster } 4 \\
\text { Eosinophilic } \\
(N=143)\end{array}$ & $\begin{array}{l}\text { Cluster } 5 \\
\text { Aspirin- } \\
\text { sensitivity } \\
(\mathrm{N}=139)\end{array}$ & $\begin{array}{l}\text { Patients } \\
\text { analysed } \\
n=1424\end{array}$ & $p$ \\
\hline More than 2 exacerbations & Yes & $442(64.1 \%)$ & $101(66 \%)$ & $185(61.9 \%)$ & $97(67.8 \%)$ & $100(71.9 \%)$ & $925(65 \%)$ & 0.26 \\
\hline \multirow{3}{*}{$\begin{array}{l}\text { Number of exacerbations } \\
\text { with increased of OCS } \\
\text { or ICS }\end{array}$} & Means $( \pm s d)$ & $2.6( \pm 3.2)$ & $2.6( \pm 3)$ & $2.2( \pm 2.6)$ & $2.9( \pm 3.6)$ & $2.9( \pm 3.1)$ & $2.5( \pm 3.1)$ & 0.03 \\
\hline & Median & 2 & 2 & 1 & 2 & 2 & 2 & \\
\hline & Min-Max & $0-20$ & $0-16$ & $0-15$ & $0-20$ & $0-20$ & $0-20$ & \\
\hline \multirow{2}{*}{$\begin{array}{l}\text { Number of hospitalizations } \\
\text { during the } 12 \text { past months }\end{array}$} & Means $( \pm s d)$ & $0.4( \pm 1.2)$ & $1( \pm 1.8)$ & $0.6( \pm 1.3)$ & $0.4( \pm 1.5)$ & $0.4( \pm 1)$ & $0.5( \pm 1.3)$ & $<0.0001$ \\
\hline & Min-Max & $0-12$ & $0-12$ & $0-12$ & $0-15$ & $0-6$ & $0-15$ & \\
\hline \multirow{2}{*}{$\begin{array}{l}\text { Number of emergency visits } \\
\text { during the } 12 \text { past months }\end{array}$} & Means $( \pm s d)$ & $0.6( \pm 1.7)$ & $0.9( \pm 2.1)$ & $0.6( \pm 1.5)$ & $0.5( \pm 1.8)$ & $0.5( \pm 1.1)$ & $0.6( \pm 1.7)$ & 0.04 \\
\hline & Min-Max & $0-20$ & $0-15$ & $0-12$ & $0-17$ & $0-6$ & $0-20$ & \\
\hline \multirow{3}{*}{$\begin{array}{l}\text { Number of medical visits } \\
\text { during the } 12 \text { past months }\end{array}$} & Means $( \pm s d)$ & $2.6( \pm 3.1)$ & $2.8( \pm 3.5)$ & $2.2( \pm 2.5)$ & $3.1( \pm 4)$ & $2.9( \pm 3.2)$ & $2.6( \pm 3.1)$ & 0.19 \\
\hline & Median & 2 & 2 & 2 & 2 & 2 & 2 & \\
\hline & Min-Max & $0-20$ & $0-20$ & $0-12$ & $0-20$ & $0-20$ & $0-20$ & \\
\hline $\begin{array}{l}\text { Absenteism related to } \\
\text { asthma during the } 12 \text { past } \\
\text { months }\end{array}$ & Yes & $113(16.4 \%)$ & 15 (9.8\%) & $24(8 \%)$ & $16(11.2 \%)$ & 21 (15.1\%) & $189(13.3 \%))$ & $<0.0001$ \\
\hline
\end{tabular}

important in cluster 2 and cluster 5 (aspirin sensitivity cluster). Obstruction of small airways was common whatever the cluster group (Table 4).

Regarding therapeutic management (Additional file 1: Table S3), a proportion of patients was still not-compliant to treatment according to Moriski scale $(<3)$. Antileukotrienes were more prescribed than anti-cholinergic treatment. The prescription of regular oral corticosteroids was higher in cluster 2 (obese patient with comorbidities). Omalizumab was prescribed in one third of the patients. A high proportion of patients had no physical activity, the greatest proportion was belong to cluster 2 (obese patients with comorbidities) (Table 5).

\section{Discussion}

In this large real-life study including difficult-to severe asthmatic patients followed by pulmonologist in nonacademic general hospitals, we described five phenotypes of patients using cluster analysis. The five cluster analysis were described cluster 1 (47\%) the most atopic with early-onset disease, cluster $2(10.5 \%)$ obese asthmatic with high prevalence of comorbidities (more than 3) including obstructive apnea syndrome, cluster 3 (20.4\%) the late-onset asthma without atopy, cluster 4 (9.8\%) eosinophilic asthma with nasal polyposis, and cluster 5 with aspirin sensitivity asthma.

Regarding the general characteristics of the population, our population is in line with what had been recently published by the International Severe Asthma Registry [13] and the ERS severe asthma registries [14]. Patients were predominantly female, with overweight or obesity, and non-smoker. Most of patients having uncontrolled asthma on GINA step 5 or on GINA step 4. $65.8 \%$ developed also asthma after 12 years old in our population compared to $77.5 \%$ in the ISAR registry. The mean number of exacerbation was higher in our population (2.5) vs (1.7) in the ISAR registry, with a significant heterogeneity across countries. Lung function before and after bronchodilator was quite similar to the ISAR global value, with little improvement after bronchodilator. Unfortunately we couldn't compare the FeNO measurements, as in our study most of practitioners could not access to this evaluation tool. In our population, $47.6 \%$ of patients had IgE lower than $200 \mathrm{UI} / \mathrm{l}$ compared to half of the ISAR registry, who had lower IgE concentration. In the same trend, $50 \%$ of our patients had a blood eosinophils count $>0.3 * 10^{9}$ cells/L. Allergic rhinitis was the predominant comorbidity, followed by reflux and hypertension. The prevalence of nasal polyps was higher in our population (18\%) vs $7.3 \%$ in the ISAR registry. We could not compare the prevalence of OSA or cardiovascular comorbidity, or osteoporosis, not reported in the ISAR publication. $16.9 \%$ of the patient received regular oral corticosteroids compared to $30.1 \%$ of the ISAR cohort. In the ISAR registry, $25.4 \%$ of the patients were on biologics, very similar to what we found in our population; however 


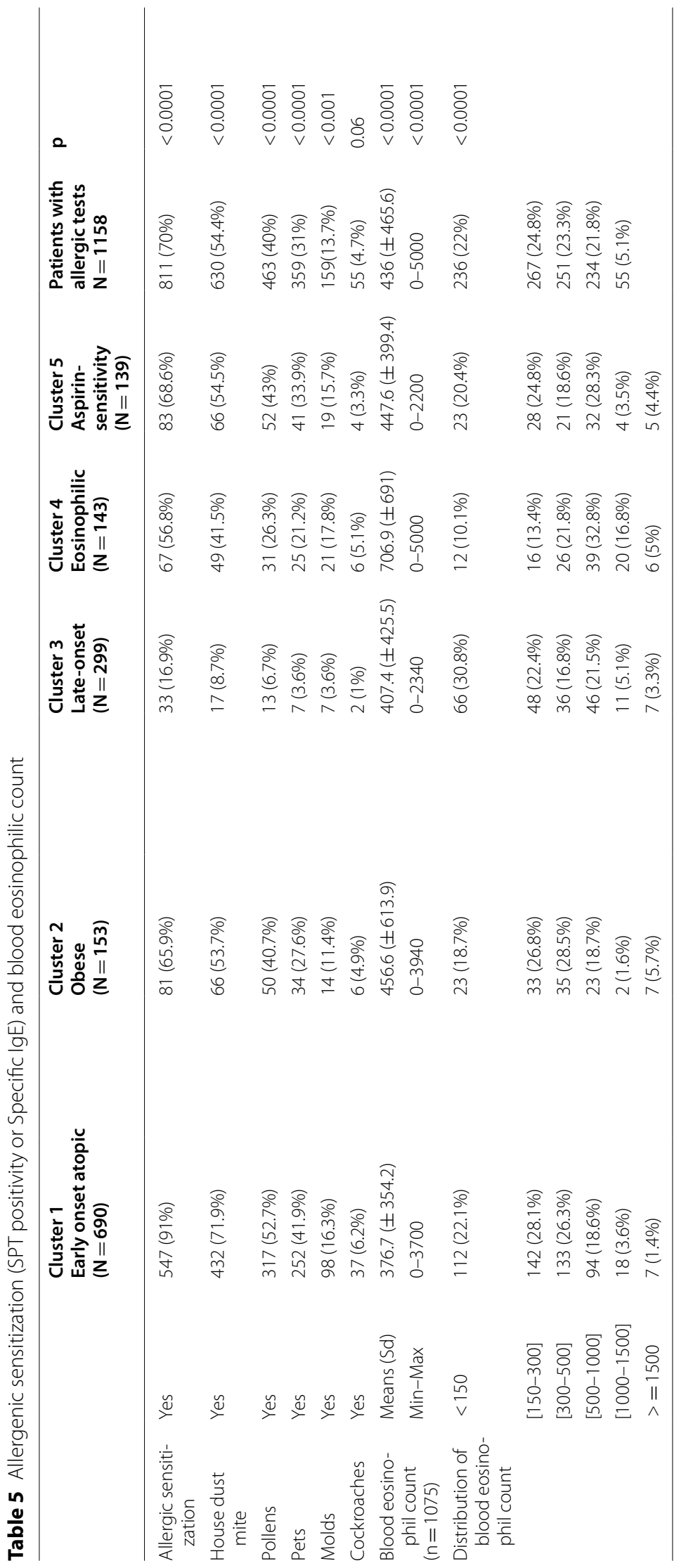


anti-IL5 was not available in France at the beginning of our study, explaining that anti-IgE was the most predominant prescription. Only $5 \%$ of patients had azithromycin prescription, lower than $9.2 \%$ of the patients from the ISAR registry.

Our cluster analysis revealed 5 clusters, 4 of them have been mostly described in previous studies: the classic early onset severe allergic asthma, the obese asthma with high impairment, the late-onset non-atopic cluster and the eosinophilic phenotype. Enfumosa Network [2] identified previously that patients with chronic severe asthma were more female, more in overweight, less atopic and pointed out exposure to aspirin for some subjects. The SARP consortium in the US identified three clusters in adult patients with severe asthma [3] using unsupervised cluster analyses: early onset allergic asthma, late onset non-atopic asthma, severe asthma with chronic airflow obstruction.Then, the TENOR project found some similarities with the SARP clusters, for four of five clusters [4] using hierarchical clustering. As us, they also identified a phenotype of adult-onset asthma with aspirin sensitivity, which is underreported in the literature. In the UK registry, five clusters [5] have been identified using a two way cluster/mixture analysis with the Bayesian information criterion: atopic early onset asthma, obese with late onset asthma, least severe asthma, eosinophilic late onset-asthma and fixed airflow obstruction. Amelink et al. [15] identified two clusters using K-means nonhierarchical cluster analysis: one with severe eosinophilic inflammation and another with frequent symptoms, high healthcare utilization and low sputum eosinophils. Newby et al. (2014) [16] identified also four clusters: early onset atopic, late-onset in obese patients, eosinophilic asthma, non-atopic with normal lung function and one group with reversible obstruction. The obese asthma phenotype has been already described, however in our analysis, we pointed out that this group was at higher risk of comorbidities, cardiovascular diseases, OSA, ex-smoker status; in addition, two third of them had more than 3 comorbidities outside ENT comorbidities. In addition, 30\% of them had prescription of oral corticosteroids, so we cannot formally exclude that this group of patients had comorbidities induced by oral steroids [17]. They also had the worse lung function regarding FEV1 or FEV1/FVC ratio before and after bronchodilatator, and the lowest physical activity compared to the other clusters. One major difference from the other studies was that in our obese cluster, atopy was present in half of the group. The UK registry [16] identified five clusters: atopic early onset asthma, obese with late onset asthma, least severe asthma, eosinophilic late onsetasthma and fixed airflow obstruction. In the eosinophilic phenotype, $20 \%$ had nasal polyps whereas in our cluster analysis $100 \%$ of the patients had nasal polyps. However, the mean of blood eosinophilic count was very similar. We described also the late-onset non-atopic asthma, which was described previously in Tenor cohort, the main difference with the Sharp study was obesity [4].

Our study had some limitations. The recruitment of severe asthmatic patients was made by pulmonologist from non-academic hospitals, not from university hospitals or primary care, so we cannot generalize the findings of our study to the whole population of severe asthmatics in France. This explained also why FeNO was not available for the majority of the centers. It is noteworthy that FeNO is not a recognized tool for monitoring asthma by the national insurance French authority at the time this paper was written. The SHARP ERS consortium found that severe asthmatic patients in Europe is heterogeneous, and differs in both clinical characteristics and treatment, most of registries enrolled patients being treated in a tertiary care center, however small centers included patients with severe asthma from primary care and second care hospitals [14].

Our statistical analysis had performed imputation algorithms to allow missing values, particularly for eosinophils counts. We made sensitivity analysis with and without imputation, the results did not change. We presented an unbiased statistical cluster analysis technique, which selects the number of the cluster based on the data. However, we must admit that bias could come from the choice of the variables included in the cluster analysis. The confidence that we have in our analysis, is that some of our clusters had been already shown in others registries, in UK or in USA. Another limit of our study is the cross-sectional design of the analysis, so we would not able to ensure stability of the clusters. In addition, there is a heterogeneity in cluster analysis (supervised vs unbiased) in the different studies that made difficult the comparison. None analysis has shown a superiority to another. The impact of OCS on blood eosinophils count is difficult to analyze, patients with OCS seem to have more eosinophils count than patients without OCS, suggesting that patients with OCS could have $\mathrm{TH} 2$ profile, compared to the others Additional file 1: Fgure S4, S5, Table S6.

\section{Conclusion}

Despite these limitations, we were able to describe five clusters in a very large population of difficult-to severe asthmatic managed by pulmonologist in non-academic hospitals in France; early onset atopic cluster, obese-late onset asthma with high comorbidities, late-onset nonatopic asthma, eosinophilic asthma with nasal polyps and aspirin sensitivity. Understanding heterogeneity of severe asthma in real life remains an important challenge to input personalized medicine, many of these patients are still excluding for the moment from randomized clinical trials. 


\section{Abbreviations}

GINA: Global initiative for asthma; BMI: Body mass index; ACT: Asthma control test; HADS: Hospital anxiety and depression scale; CRF: Case report form; ICU: Intensive Care Unit; FEV1: Flow expiratory volume; IgE: Immunoglobulin E; FEV1/FVC ratio: Flow expiratory volume/forced vital capacity; OCS: Oral corticosteroids; ICS: Inhaled corticosteroids; ENT: Ear-nose-throat; OSA: Obstructive syndrome apnea; FeNO: Exhaled fraction NO.

\section{Supplementary Information}

The online version contains supplementary material available at https://doi. org/10.1186/s12931-021-01723-x.

Additional file 1: Table S1. Blood eosinophils count and lgE levels in FASE severe asthma patients. Table S2. Spirometric profiles and FASECPHG severe asthma clusters. Table S3. Therapeutic management and FASE-CPHG severe asthma clusters. Figure S4. Distribution of vems by cluster. Figure S5. Distribution of eosinophils by cluster. Table S6. Blood count eosinophils according to OCS

\section{Acknowledgements}

The authors thank the FASE-CPHG participants and participating investigators and staff for making this study possible. The participating physicians are : Dr Appere De Vecchi (CH Argenteuil); Dr Maurer (CH Montfermeil); Dr Lepoulain Doubliez (CH Charleville Mezières); Dr lamandi (CH Mulhouse); Dr Gourcerol (CH Pau); Dr Didi. Dr Decroisette and Dr Bertocchi (CH Pringy); Dr Moreau (CH Colmar); Dr Barbare and Dr Moncelly (CH Meaux); Dr Tannous (CH Forbach); Dr Kelkel (CH Chambéry); Dr Rolland (CH Cannes); Dr Jouveshomme (Hôpital St-Joseph. Paris); Dr Bernier (CH Dinan); Dr Hauss. Dr Ould. Dr Vincent. Dr Van Mossevelde and Dr Gallego (CH Elbeuf); Dr Merzoug (CH Fougères); Dr Haddad (CH Lourdes); Dr Allibe (CH Colmar); Dr Guerrero. Dr Jarjour. Dr Haouachi and Dr Goutorbe (CH Béziers); Dr Morel. Dr Lemaire and Dr Russier (CH Orléans); Dr Roge (CH Morlaix); Dr Dumont (CH Chauny); Dr Cavestri and Dr Just (CH Roubaix); Dr Colin (CH Versailles); Dr Goupil. Dr Mansour and Dr Paris (CH Le Mans); Dr Philippe and Dr Boitiaux (CH Cergy-Pontoise); Dr Simon (CH Compiègne); Dr Marcq. Dr Bizieux. Dr Guibert and Dr Caby (CH La Roche sur Yon); Dr Lecuyer (CH Saint-Quentin); Dr Merlusca (CH Sedan); Dr Roy (CH Libourne); Dr Blanc (CH Aix en Provence); Dr Langelot (CH Les Sables d'Olonne); DrTagu (CH Bar le Duc); Dr Leveiller. Dr Duriel-Niel and Dr Coëtmeur (CH Saint-Brieuc); Dr Ilie (CH Dunkerque); Dr Raspopa (CH Toulon); Dr Courdeau-Labourie and Dr Demaegdt (CH Tarbes); Dr Lerousseau and Dr Rotomondo (CH Antibes); Dr Gramada (CH Sarreguemines); Dr Cornu and Dr Petit (CH Verdun); Dr Kraemer (CH Fréjus); Dr Huy (CH Vannes); Dr Gentil. Dr Lucian and Dr Lucena (CH Bourgoin Jallieu); Dr Michaux (CH Macon); Dr Maitre (CH Vesoul); Dr De Faverges (CH Nevers); Dr Fouret (CH Villeneuve Saint-Georges); Dr Goarant (CH Saint-Malo); Dr Bara and Dr Hamoudi (CH Angoulême); Dr Maetz (CH Douai); Dr Yousef and Dr Lungoci (CH Le Puy en Velay); Dr Al Freijat (CH Belfort); Dr Assemi (CH Saverne); Dr Beysens (CH Saintes); Dr Clarissou (CH Beaumont sur Oise); Dr Karimo (CH Saint-Omer); Dr Saadi (CH Barbezieux Saint Hilaire); Dr Barre and Dr Farny (CH Cahors); Dr Romand (CH Contamine sur Arve); Dr Leleu (CH Abbeville); Dr Bernard (CH Quimper); Dr Marangoni (CH Saint-Dié); Dr Fevrier (CH Saumur); Dr Paillot (CH Metz); Dr Bonnefoy (CH Jonzac); Dr Manoila (CH Evreux); Dr Abraham (CH Dax); Dr Lacroix (CH Périgueux); Dr Virally (CH Aulnay sous Bois). The authors would like to thank Mrs. Vanessa Cohignac. Mrs. Hélène Le Cloarec. Mrs. Mathilde Pouriel and Mrs. Nathalie Texier from Kappa Santé, a contract research organization, for the operational management of the study, data analysis. preparation of the study report and the present article. The authors would also like to share compassionate thought for Juliette Ostinelli.

\section{Authors' contributions}

$C R$, contribute to the conception, the statistical analysis and wrote the paper. $E P, C N, G M, A P, J P O, A V C, C M, D D, L P$ contribute to the conception of the study, inclusion of the patients. All authors read and approved the final manuscript.

\section{Funding}

FASE-CPHG study was supported by contributions made through the CPHG from ALK. AstraZeneca. Boehringer Ingelheim. GSK and Le Nouveau Souffle. The funding bodies had no role on the conception of this manuscript, they did not participate in any way in the design of the study, the analysis of the results or writing or revision of the manuscript.

\section{Availability of data and materials}

The database is available upon request at Kappa Santé a contract research organization.

\section{Declarations}

\section{Ethics approval and consent to participate}

This study was approved by the local ethics committee (Comité Consultatif sur le Traitement de l'Information en matière de Recherche dans le domaine de la Santé (CCTIRS)) and was conducted according to the French law and guidelines on epidemiological and descriptive studies.

\section{Consent for publication}

Not applicable.

\section{Competing interests}

The authors declare that they have no competing interests.

\section{Author details}

${ }^{1}$ Groupe Hospitalier Sud, Hôpital Haut-Lévêque CHU Bordeaux, Pessac, France. ${ }^{2}$ INSERM U1219 Université de Bordeaux, Bordeaux, France. ${ }^{3}$ Centre Hospitalier de Polynésie Française, Hôpital du Taaone, Papeete, French Polynesia. ${ }^{4}$ Centre Hospitalier de la Côte Basque, Bayonne, France. ${ }^{5}$ Service de Pneumologie, Centre Hospitalier Intercommunal de Créteil, Créteil, France. ${ }^{6}$ Clinique Médicale et Cardiologique d'Aressy, Pau, France. ${ }^{7}$ Service de Pneumologie, Centre Hospitalier Louis Pasteur, Colmar, France. ${ }^{8}$ Centre Hospitalier d'Argenteuil, Argenteuil, France. ${ }^{9} \mathrm{GHI}$ Montfermeil, Montfermeil, France. ${ }^{10}$ Service de Pneumologie, Groupe Hospitalier de la Région Mulhouse Sud-Alsace, Hôpital Émile Muller, Mulhouse, France. ${ }^{11}$ Centre Hospitalier Robert Boulin de Libourne, Site Robert Boulin, Libourne, France.

Received: 28 August 2020 Accepted: 16 April 2021

Published online: 04 May 2021

\section{References}

1. Global Strategy for Asthma Management and Prevention, Revised 20182018; www.ginasthma.org: 2018 Global Initiative for Asthma.

2. The ENFUMOSA cross-sectional European multicentre study of the clinical phenotype of chronic severe asthma. European Network for Understanding Mechanisms of Severe Asthma. Eur Respir J. 2003;22(3):470-7.

3. Fitzpatrick AM, Moore WC. Severe asthma phenotypes-how should they guide evaluation and treatment? J Allergy Clin Immunol Pract. 2017:5(4):901-8.

4. Schatz M, Hsu JW, Zeiger RS, Chen W, Dorenbaum A, Chipps BE, et al. Phenotypes determined by cluster analysis in severe or difficult-to-treat asthma. J Allergy Clin Immunol. 2014;133(6):1549-56.

5. Heaney LG, Brightling CE, Menzies-Gow A, Stevenson M, Niven RM. British Thoracic Society difficult asthma N. Refractory asthma in the UK: crosssectional findings from a UK multicentre registry. Thorax. 2010;65(9):787-94.

6. Schleich F, Brusselle G, Louis R, Vandenplas O, Michils A, Pilette C, et al. Heterogeneity of phenotypes in severe asthmatics. The Belgian Severe Asthma Registry (BSAR). Respir Med. 2014;108(12):1723-32.

7. Maio S, Baldacci S, Bresciani M, Simoni M, Latorre M, Murgia N, et al. RltA: the Italian severe/uncontrolled asthma registry. Allergy. 2018;73(3):683-95.

8. Fabry-Vendrand C, Didier A. Asthma prevalence and management in adults in France in 2018: ASTHMAPOP survey. Eur Respir J. 2018;52(Suppl62):OA292. https://doi.org/10.1183/13993003.congress-2018. OA292.

9. Hekking PP, Wener RR, Amelink M, Zwinderman AH, Bouvy ML, Bel EH. The prevalence of severe refractory asthma. J Allergy Clin Immunol. 2015;135(4):896-902.

10. von Bulow A, Kriegbaum M, Backer V, Porsbjerg C. The prevalence of severe asthma and low asthma control among Danish adults. J Allergy Clin Immunol Pract. 2014;2(6):759-67. 
11. Brown T, Jones T, Gove K, Barber C, Elliott S, Chauhan A, et al. Randomised controlled trials in severe asthma: selection by phenotype or stereotype. Eur Respir J. 2018;52(6):1801444. https://doi.org/10.1183/13993003.01444-2018.

12. Portel L, Parrat E, Nocent-Ejnaini C, Mangiapan G, Prud'homme A, Oster JP, et al. FASE-CPHG study: a panoramic snapshot of difficult-to-treat, severe asthma in French nonacademic hospitals. ERJ Open Res. 2019;5(4):000692019. https://doi.org/10.1183/23120541.00069-2019.

13. Eileen W, Wechsler ME, Tran TN, Heaney LG, Jones RC, Menzies-Gow AN, et al. Characterization of severe asthma worldwide: data from the International Severe Asthma Registry (ISAR). Chest. 2019;157(4):790-804.

14. van Bragt J, Adcock IM, Bel EHD, Braunstahl GJ, Ten Brinke A, Busby J, et al. Characteristics and treatment regimens across ERS SHARP severe asthma registries. Eur Respir J. 2019;54(Suppl63):OA5354. https://doi.org/10.1183/ 13993003.congress-2019.OA5354

15. Amelink M, de Nijs SB, de Groot JC, van Tilburg PM, van Spiegel PI, Krouwels FH, et al. Three phenotypes of adult-onset asthma. Allergy. 2013;68(5):674-80
16. Newby C, Heaney LG, Menzies-Gow A, Niven RM, Mansur A, Bucknall C, et al. Statistical cluster analysis of the British Thoracic Society Severe refractory Asthma Registry: clinical outcomes and phenotype stability. PLoS ONE. 2014;9(7):e102987.

17. Sweeney J, Patterson CC, Menzies-Gow A, Niven RM, Mansur AH, Bucknall $C$, et al. Comorbidity in severe asthma requiring systemic corticosteroid therapy: cross-sectional data from the Optimum Patient Care Research Database and the British Thoracic Difficult Asthma Registry. Thorax. 2016;71(4):339-46.

\section{Publisher's Note}

Springer Nature remains neutral with regard to jurisdictional claims in published maps and institutional affiliations.
Ready to submit your research? Choose BMC and benefit from:

- fast, convenient online submission

- thorough peer review by experienced researchers in your field

- rapid publication on acceptance

- support for research data, including large and complex data types

- gold Open Access which fosters wider collaboration and increased citations

- maximum visibility for your research: over 100M website views per year

At BMC, research is always in progress.

Learn more biomedcentral.com/submissions 